\title{
Alteraciones del paisaje ecológico araucano por la asimilación mapuche de la agroganadería hispano-mediterránea (siglos XVI y XVII)
}

\author{
Araucanian ecological landscape disturbances by the mapuche assimilation of the \\ Hispanic-Mediterranean farming $\left(16^{\text {th }}\right.$ and $17^{\text {th }}$ centuries $)$
}

\author{
FERNANDO TORREJÓN ${ }^{1} \&$ MARCO CISTERNAS $^{2}$ \\ ${ }^{1}$ Centro de Ciencias Ambientales EULA-Chile, Universidad de Concepción, \\ Casilla 160-C, Concepción, Chile; e-mail: ftorrejo@udec.cl \\ ${ }^{2}$ Facultad de Agronomía, Universidad Católica de Valparaíso, Casilla 4-D, Quillota, Chile; \\ e-mail: marco.cisternas@ucv.cl
}

\begin{abstract}
RESUMEN
Las características biogeográficas de la América templada favorecieron la introducción y propagación de especies animales y vegetales que sustentaron al modelo agroganadero hispano-mediterráneo. Los efectos de este fenómeno generaron alteraciones ecológicas, especialmente en los territorios habitados por aborígenes carentes de actividades productivas intensivas, como fue el caso de la Araucanía. Mediante un análisis histórico documental, la presente investigación reconoció las principales características del proceso de alteración del paisaje ecológico araucano entre los siglos XVI y XVII: (i) en el siglo XVI, la introducción de especies exóticas desarticuló el sistema económico mapuche, (ii) tanto la relativa pristinidad de la Araucanía como el proceso bélico de los siglos XVI y XVII, favorecieron la introducción y propagación de las nuevas especies, (iii) durante el siglo XVI coexistieron especies nativas e introducidas, sin embargo, durante el siglo XVII preponderaron las exóticas, y (iv) este predominio habría generado la extinción local de especies animales y vegetales nativas, alterando definitivamente el paisaje ecológico araucano.
\end{abstract}

Palabras clave: ecología del paisaje, introducción de especies, colonización española, Araucanía, Chile.

\begin{abstract}
The bio-geographic characteristics of the temperate America favored the introduction and spreading of exotic plant and animal species that supported the Hispanic-Mediterranean farming model. The effects of this situation produced ecological alterations on the territories inhabited by Indians without intense productive systems; as the Araucanía case. Through a historical and documental analysis this paper reports the main characteristics of the Araucanian ecological landscape disruption process during the $16^{\text {th }}$ and $17^{\text {th }}$ centuries: (i) during the $16^{\text {th }}$ century, the introduction of exotic species dislocated the Mapuche economic system, (ii) both the relative Araucanía pristine conditions and the warlike process, occurred between the $16^{\text {th }}$ and $17^{\text {th }}$ centuries, favored the introduction and spreading of the new species, (iii) during the $16^{\text {th }}$ century, both natives and exotic species coexisted, but during the next century the exotic species predominated, and (iv) this preponderance would have produced a local extinction of native plants and animals, disrupting definitively the Araucanian ecological landscape.
\end{abstract}

Key words: ecological landscape, species introduction, Spanish settlement, Araucanía, Chile.

\section{INTRODUCCIÓN}

Una de las principales características de la colonización española de América fue la temprana introducción de especies vegetales y animales, desconocidas en los sistemas productivos y biodiversidad precolombinas (Latcham 1922, 1936). Junto al proceso colonizador se afianzó, especialmente en la América templada-debido a sus favorables características biogeográficas-, el modelo agropecuario hispano-mediterráneo. Cultivos intensivos (e.g., trigo, vid), y ganadería de ungulados (e.g., bovinos, equinos, ovinos y caprinos) estructuraron este nuevo sistema (Cunill 1970, 1971, Chonchol 1994).

Las prácticas introducidas generaron tempranas alteraciones ambientales en los ecosistemas americanos. Sus consecuencias fueron más drásticas en los territorios relativamente prístinos, habitados por aborígenes carentes de actividades productivas intensivas. No obstante lo anterior, la progresiva asimilación indígena de dichas prácticas habría contribuido a la subsistencia de algunas etnias afectadas por la conquista (Zapater 1985, Martínez 1998). 
En Chile, con la penetración española al sur del río Biobío durante la segunda mitad del siglo $\mathrm{XVI}$, los mapuches adoptaron nuevas especies vegetales y animales, las que fueron vitales para su supervivencia e independencia hasta inicios de la República (Bengoa 1991). Sin embargo, como se pretende demostrar en el presente artículo, este proceso habría producido además tempranas e importantes alteraciones ambientales en el territorio mapuche. Los resultados de este ejercicio servirán para comprender, de mejor manera, la dinámica temporal de los procesos degradativos que actualmente afectan al paisaje ecológico de la Araucanía.

\section{MATERIALES Y MÉTODOS}

\section{Definición del área de estudio}

El área de estudio comprende al territorio históricamente ocupado por los mapuches (siglos XVIXIX), cuyos límites eran los ríos Itata, por el norte, Toltén por el sur, la cordillera de Los Andes por el este y el Océano Pacífico por el oeste $\left(36^{\circ} 30^{\prime}\right.$ $39^{\circ} 00^{\prime} \mathrm{S}, 71^{\circ} 30^{\prime}-73^{\circ} 15^{\prime} \mathrm{O}$ ). Dicho territorio fue conocido como "La Araucanía", según la denominación otorgada por los españoles (Krumm 1971, 1972). Actualmente, la Araucanía, con un área aproximada de $50.000 \mathrm{~km}^{2}$, forma parte de la Octava Región del Biobío y Novena Región de la Araucanía, centro-sur de Chile (Fig. 1).

\section{Análisis bibliográfico}

Se efectuó una recopilación, selección y análisis del material bibliográfico disponible, privilegiándose la información testimonial de fuentes históricas de primer orden, como las crónicas y documentación epistolar de los siglos XVI y XVII. Del mismo modo, fue relevante el uso de las fuentes historiográficas y de naturalistas coloniales (siglos XVII y XVIII), junto a monografías contemporáneas (siglo XX).

\section{RESULTADOS Y DISCUSIÓN}

\section{Paisaje ecológico prehispánico}

Hacia 1550 los recursos de la Araucanía eran capaces de alimentar a una población indígena estimada en 500.000 personas; mayoritariamente asentadas en la llanura costera y en ambas vertientes de la cordillera de Nahuelbuta, entre los ríos Biobío e Imperial (Bengoa 1991).
Las condiciones biogeográficas de la Araucanía, en especial las climáticas y vegetacionales, permitieron a los mapuches - una sociedad tribal neolítica (Berdichewsky 1971, Villalobos 1995, Mostny 1996)- desarrollar una economía diversificada, que se sustentó en la recolección, caza, pesca, agricultura incipiente y crianza de la llama (Lama lama). Estas dos últimas actividades productivas, aunque ampliamente difundidas, fueron principalmente de autoconsumo (Villalobos 1983, Bengoa 1991, Chonchol 1994).

En carta del 25 de septiembre de 1551, Pedro de Valdivia señalaba al rey que la Araucanía era "próspera de ganados como lo del Perú [...]; abundosa de todos los mantenimientos que siembran los indios para su sustentación, así como maíz, papas, quinua, mare, ají y frisoles". ${ }^{1}$ Observación reforzada, en 1558, por la crónica de Jerónimo de Vivar: "los naturales tienen mays y frisoles y papas y vna yerva a manera de avena, qu'es buen mantinimiento para ellos. Son muy grandes labradores y cultivan muy bien la tierra". ${ }^{2}$

El éxito de esta incipiente agricultura se debió fundamentalmente a que los mapuches aprovecharon las favorables características del paisaje araucano. De acuerdo a Bengoa (1991), éstos utilizaban principalmente los claros de bosque y fértiles terrenos de vegas para el cultivo de sus productos, mientras que el riego era proporcionado por la natural abundancia de lluvias. Autores como Donoso \& Lara (1997) indican que los mapuches también hicieron uso agrícola de distintas "áreas despobladas de bosques" en ambas vertientes de la cordillera de Nahuelbuta y Llano Central; señalando que, entre otros lugares, dichos "campos abiertos" se ubicaban en Arauco, Angol, Purén y en los valles de los ríos Biobío y Cautín.

Paralelamente, la relativa simplicidad de herramientas y técnicas involucradas en la producción

${ }^{1}$ VALDIVIA, PEDRO DE: “Cartas que tratan del descubrimiento y conquista de la Nueva Extremadura". Edición facsímil realizada en conmemoración del Quinto Centenario del Encuentro de Dos Mundos, al cuidado de Miguel Rojas-Mix, Editorial Andrés Bello, España, 1991, p.166.

${ }^{2}$ VIVAR, JERÓNIMO DE: “Crónica y relación copiosa y verdadera de los Reinos de Chile (1558)". Edición de Leopoldo Sáez-Godoy, Biblioteca Ibero-Americana, Colloquium Verlag, Berlín, Alemania, 1970. p. 182. 

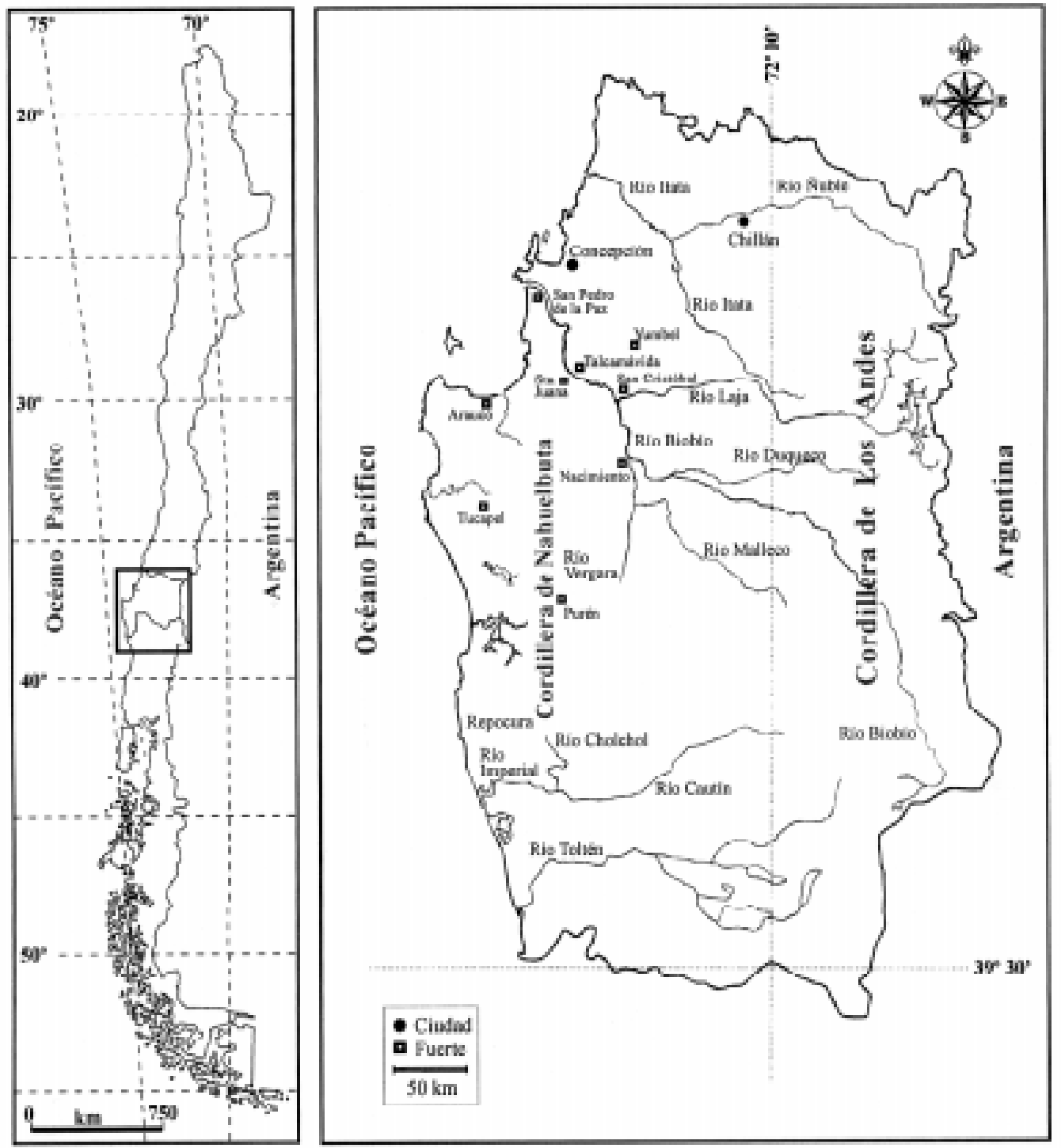

Fig. 1: La Araucanía hacia fines del siglo XVII.

The Araucania at the end of the XVII century.

agrícola mapuche, sumadas al carácter extensivo de los cultivos, permitió la sustentabilidad del sistema (Latcham 1936, Bullock 1958, Bengoa 1991). Las rotaciones y diversidad de especies vegetales habrían promovido también la retención de nutrientes del suelo y mecanismos de auto control biológico. Desde el punto de vista del paisaje, los policultivos indígenas se caracterizaban por ser miméticos, complejos e integrativos, imitando a los ecosistemas naturales, que no eran agredidos con trabajo animal ni arado. ${ }^{3}$

Respecto a la ganadería, se trataba de una faena criancera extensiva y de pequeña escala. Las llamas (chilihueques u ovejas de la tierra), además de la carne, proporcionaban materias primas in- dispensables (e.g., lana) para cubrir las necesidades básicas de los indígenas. Aún cuando esta actividad de crianza se encontraba ampliamente expandida entre las familias mapuches (Bengoa 1991), Latcham (1922) reconoce que, raramente, se podía encontrar un rebaño individual que superara los cincuenta animales.

\footnotetext{
${ }^{3}$ Apuntes Curso de Postgrado "Ambiente sociedad y economía: las variables geohistóricas americanas. Siglos XV-XIX”. Dictado por el Dr. Pedro Cunill G., en el Centro EULA-Chile, Universidad de Concepción, Concepción, Chile, marzo de 1999.
} 
Del análisis anterior se infiere que la actividad agropecuaria mapuche estuvo en un relativo equilibrio con el medio natural, debido a su carácter extensivo y de autoconsumo. Posteriormente, la irrupción de la agroganadería hispano-mediterránea provocó la desarticulación del sistema económico indígena, comenzando un acelerado proceso de alteración del paisaje ecológico araucano.

\section{Introducción de especies exóticas y sus efectos ambientales en la Araucanía.}

En 1550 Pedro de Valdivia fundó Concepción del Nuevo Extremo en el sitio de Penco, ciudad que se constituyó en el primer asentamiento hispano permanente en la Araucanía. La resistencia mapuche a la nueva ocupación originó la denominada Guerra de Arauco (Villalobos 1995), conflicto en el cual los españoles establecieron enclaves militares (Guarda 1990), que sustentaron la explotación sistemática de la Araucanía.

De acuerdo al criterio de los conquistadores, los recursos naturales de la Araucanía y su población debían ser económicamente aprovechados. Inicialmente, la explotación aurífera fue la principal actividad productiva (Villalobos 1983); sin embargo, los lavaderos de oro se agotaron rápidamente, mientras que la resistencia mapuche se incrementó. Ambos factores obligaron a los hispanos a readecuar su "economía de conquista", acelerando la introducción de nuevas especies; para evolucionar desde la simple explotación del recurso natural a la intensificación de las prácticas agropecuarias hispano-mediterráneas (Pacheco 1991).

La introducción y adaptación de especies vegetales de origen mediterráneo en la Araucanía, son tempranamente reconocidas hacia 1558: "Dase mucho trigo y çebada [...]. Dase toda la ortaliza de nuestra España y legumbres. Y anse puesto sarmientos y danse muy bien, y higueras. Y se daran todas las demas plantas de nuestra España muy bien, porque el temple es muy bueno". ${ }^{4}$

La introducción de especies animales también fue parte de la intensificación agropecuaria en la Araucanía. La abundancia de forraje natural y la ausencia de grandes competidores y depredadores -el puma (Puma concolor) era el único carnívoro de importancia-fueron determinantes en la propagación de caballares, vacunos, ovinos y caprinos. A fines del siglo XVI, el cronista Mariño de Lobera señalaba que: "Todas estas tierras de Arauco y Tucapel, y las demás circunvecinas son tan excelentes en todo [...], pues todo está lleno de mantenimientos de los hombres y cuando menos de pastos para los ganados, donde hai ovejas sin número, y otras muchas reses, fuera del ganado vacuno que despues de la entrada de los españoles, es tan sin tasa, que se lo lleva de balde el que lo quiere". 5

De igual modo, los mapuches adoptaron, consciente y deliberadamente, cultivos y animales de crianza españoles; sustituyendo especies autóctonas que habían sido esenciales en su economía. Paulatinamente, se fueron restringiendo los cultivos de maíz (Zea mais), quínoa (Chenopodium quinoa) y madi (Madia sativa); desapareciendo variedades de grano como el mango (Bromus mango) y la "teca" o "tuca" 6 (Latcham 1936, Bullock 1958). Del mismo modo, algunas especies animales sufrieron desapariciones locales, como lo reconoce el cronista Vivar en 1558: "Quando entramos en esta tierra los españoles avia ganado [1lamas], avnque no mucho, y con las guerras se an acabado, por lo qual no ay agora ninguno, [a-sino] qual o qual, porque donde entran españoles, espeçialmente en conquistas son como las langostas en los panes". ${ }^{7}$

No obstante lo anterior, los cronistas observan también la coexistencia de especies nativas e introducidas. En 1600, Fray Diego de Ocaña reconoció que, al sur del Biobío, los valles eran "fertilísimos de mantenimientos de la tierra como maíz, papas, trigo y cebada y ganado ovejuno de castilla y de la tierra". ${ }^{8}$ En los humedales de Purén, al interior de la Araucanía, Ocaña vió además que los mapuches poseían "ganado ovejuno y porcino y algunos cabríos". ${ }^{9}$

${ }^{4}$ VIVAR, JERÓNIMO DE: Op. cit. p. 182.

${ }^{5}$ MARIÑO DE LOBERA, PEDRO: "Crónica del Reino de Chile”. En: Colección de Historiadores de Chile, Imprenta del Ferrocarril, Santiago, 1865, tomo VI. p. 123.

${ }^{6}$ Se cree que la "teca" era un tipo de cereal, endémico del centro-sur de Chile, que fue cultivado por los mapuches desde tiempos precolombinos y de cuya molienda se obtenía una especie de harina. Según lo documenta Latcham (1936), su cultivo habría sido abandonado durante el s. XVIII; quedando dicha planta "sin clasificar".

${ }^{7}$ VIVAR, JERÓNIMO DE: Op. cit. p. 186.

${ }^{8}$ OCAÑA, DIEGO DE. "Viaje a Chile. Relación del viaje a Chile, año de 1600, contenida en la crónica de viaje intitulada 'A través de la América del Sur' ". Editorial Universitaria, Santiago, Chile, 1995. pp. 37-38.

${ }^{9}$ Ibid., p. 38. 
El siglo XVI finaliza con el alzamiento general mapuche de 1598, que consolidó el dominio indígena entre los ríos Biobío y Toltén. Entre 1598 y 1604 todos los asentamientos hispanos, al sur del Biobío, fueron destruidos o abandonados (Guarda 1978, Villalobos 1995). Esta insurrección favoreció la propagación de los cultivos y ganados exóticos en la Araucanía. Por una parte, los mapuches obtuvieron un gran número de animales de crianza como botín; estimándose que, entre 1598 y 1600 , se apropiaron de al menos 500.000 cabezas, incluyendo porcinos, caprinos, ovinos y bovinos (Encina \& Castedo 1964). Por otra, se apoderaron de importantes cantidades de semillas introducidas, lo que les permitió extender, en desmedro de las especies nativas, los cultivos del trigo y cebada.

Testigo de este proceso fue el cronista González de Nájera: "ya de poco tiempo a esta parte se han comenzado a desquitar y pagar de su mano con haber dado principio a sustentarse de nuestras propias y legítimas semillas que llevaron de España los nuestros a aquella tierra, que son nuestros trigos y cebadas de harto más sustancia que sus maíces, proveyéndose también de nuestras cabras y carneros llevados asimismo de España. [...] y así fueron procurando acaudalar las cantidades que pudieron por algunos años, así en sus particulares cautelosas paces, como en el saco de las ciudades que destruyeron. Las cuales semillas multiplicaron, como lo hacen maravillosamente en aquella fértil tierra". ${ }^{10}$ Agregando más adelante: "tampoco abundaron jamás de tanta carne, como al presente poseen; pues por maravilla hay familia de indios que no posea un rebaño de ganado de nuestras cabras y carneros [...], habido todo de la manera en que acaudalaron el trigo y cebada.". ${ }^{11}$

La preferencia de los indígenas por las especies introducidas obedeció a razones eminentemente prácticas. La abundancia de granos (principalmente trigo y cebada) y de ganados mayores y menores criados en las estancias fronterizas de Chillán, Itata y Concepción; sumada a la cierta facilidad para apropiarse de ellos, mediante incursiones depredatorias (Latcham 1915), permitió a los mapuches suplir con creces las pérdidas de cultivos y ganado autóctono expoliados por los conquistadores.

En el mismo sentido se debe destacar también el uso oportunista que los mapuches hicieron de las nuevas especies, para enfrentar en mejores condiciones a los españoles. En efecto, es indudable que la adopción del caballo mejoró significativamente la capacidad guerrera de estos indígenas (Latcham 1915, Leiva 1981-1982); mientras que la tenencia de ganado menor les ayudaba a sustentar su economía doméstica. Más aún, frente a la persistencia de los españoles por intentar dominar la Araucanía, la asimilación del cultivo del trigo y la cebada fue particularmente relevante en la estrategia de resistencia mapuche.

Durante la Guerra de Arauco los soldados españoles incursionaban profundamente en el territorio mapuche buscando causar el mayor daño posible a los indígenas. Mediante la táctica de las "campeadas" o incursiones punitivas, realizadas de manera preferente en la favorable estación de verano, los españoles atacaban directamente las parcialidades mapuches intentando destruir su economía para someterlos. En este contexto y percibiendo las ventajas que ofrecía la asimilación de cultivos cerealeros introducidos, los mapuches los aprovecharon hábilmente para contrarrestar la táctica hispana.

El ya citado cronista González de Nájera, quien como militar participó activamente en las campeadas a inicios del siglo XVII, registró en detalle las causas y efectos de la ingeniosa medida adoptada por los mapuches, anotando que "como el maíz que antes era el nervio principal de su sustento, es de su calidad fruto tardío, y requiere ser sembrado en tierras no solamente bajas y llanas, pero húmedas y frescas (así como vegas y cañadas), reconociendo los indios estas sus cualidades, y que eran causas que por mucho que dilatase nuestra gente cada verano sus usadas salidas a campear aguardando a que hubiese yerva en los campos del largo camino para el sustento de nuestra caballería, con todo ello no dejaba siempre de llegar a sus tierras a sazón que lo estaban en la que se había de coger sus maíces; y por requerir también las tierras que dije llanas, eran fáciles de hallar de los nuestros, no solo para el sustento del campo, pero para talar y destruir cuantas vegas dellos se hallaban, para necesitarlos a que dieran la paz, considerando, pues, los mismos indios cuán patente y manifiesto tenían para los nuestros su principal sustento, y no ignorando que nuestros trigos y cebadas no requerían tanto regalo como sus maíces, y que no les eran inferiores en bondad de mantenimiento, y que principalmente eran de mucho más temprana cogida para lo que era el no hallarlos por segar nuestro campo como sus maíces". ${ }^{12}$ Indicando que esto permitía a los mapuches sembrar "sus trigos y cebadas en

\footnotetext{
${ }^{10}$ GONZÁLEZ DE NÁJERA, ALONSO: "Desengaño y reparo de la guerra del Reino de Chile". Editorial Andrés Bello, Santiago, Chile, 1971. pp. 175-176.

${ }^{11}$ Ibid. pp. 177-178.

${ }^{12}$ Ibid. p. 176.
} 
várias hazas divididas en sus muchos cerros no poco trabajosos y dificultosos de subir. Lo segundo, por su madurar tan temprano como dije, respecto de sus tardíos maíces, cuando nuestro campo sale a campear, todo se halla segado y la cosecha puesta en cobro enterrada en sus ocultos silos, donde acostumbran los indios a conservarla para el mantenimiento de su año". ${ }^{13}$

En síntesis, la Guerra de Arauco contribuyó a expandir los cultivos y ganados de origen hispano-mediterráneos al interior del territorio mapuche, demostrando además la notable capacidad de asimilación y adaptación que poseían aquellos indígenas.

\section{Alteraciones en el paisaje ecológico araucano del siglo XVII}

El proceso anteriormente descrito habría producido notorias modificaciones en el paisaje ecológico de la Araucanía del siglo XVII. A medida que los indígenas aumentaron su capacidad agropecuaria, fueron intensificando la presión de uso del territorio; sembrando y sometiendo al pastoreo áreas anteriormente prístinas o con poca intervención: "de tal manera vinieron a poseer por todas partes tanta cantidad, que no solamente han venido a tener abundantísima cosecha de lo necesario para su sustento, pero les sobra ya tanto trigo y cebada, que dejan muchas veces perder grandísimas hazas de ambas semillas, de que yo fui testigo el año de mil y seiscientos y dos, que el gobernador Alonso de Ribera llegó con el campo a la fértil provincia de Purén, donde del año precedente se veían fertilísimos trigos y cebadas por segar, cuyas gruesas espigas estaban denegridas de las lluvias y fríos del pasado invierno, por no haberlas segado los indios, como cosa sobrada para su menester". ${ }^{14}$

Del mismo modo, los mapuches ya no sólo sembraron en terrenos planos bajos y húmedos (vegas), como lo hacían tradicionalmente, sino que empezaron a utilizar sectores altos, más frágiles, con pendientes fuertes: "Así que abundan de tal manera los indios de guerra de nuestros trigos y cebadas, que por sus propiedades han ido dejando casi del todo sus regalados maíces, viendo no solamente que todo terreno era apropiado para nuestras semillas, ora fuere bajo, llano, ladera o cumbre de cerro". ${ }^{15}$

El paisaje araucano sufrió quizás una de las más importantes transformaciones con la presencia de los ungulados, que con sus hábitos alimenticios y de movilidad generaron importantes cambios ecológicos en los hábitats originales. De acuerdo a Díaz et al. (1987), a nivel de cobertura vegetal, los camélidos domésticos producían un bajo impacto en los ecosistemas debido a una característica anatómica fundamental como sus "almohadillas plantares", que reducían el "efecto de pisoteo"; y a la variedad de especies elegidas para su alimentación. Por el contrario, las pesuñas de los ungulados introducidos, así como su selectividad alimenticia, sobre todo la de caballares y vacunos, debieron haber generado impactos mucho mayores sobre el suelo y determinadas comunidades vegetales.

Intuitivamente, González de Nájera reconoció la relación entre el paisaje prístino araucano y el ganado introducido; refiriéndose a la caballada señala: "consérvanla agora aquellos bárbaros con gran comodidad y aumento, porque tienen hermosísimos pastos de campos, valles y quebradas, que en todo tiempo los cubre fresca y viciosa yerba, donde apacientan sus caballos en gran copia gordos, gallardos y lozanos". ${ }^{16}$ También se percató de cómo ciertas condiciones geográficas favorecieron a determinadas especies introducidas: "por maravilla hay familia de indios que no posea un rebaño de ganado de nuestras cabras y carneros, que también llevaron los nuestros de España a aquella tierra, según ya dije, y especialmente de cabras por ser ganado tan a propósito para la aspereza de sus tierras [...]. El cual ganado multiplica maravillosamente entre ellos". ${ }^{17}$

El aumento de ungulados en el paisaje araucano trajo consigo, necesariamente, la disminución de la llama (oveja de la tierra); animal que probablemente caracterizaba el paisaje prehispánico, debido a su condición doméstica. Este hecho se refleja en el estatus social que otorgaba su tenencia, como lo reconoce Núñez de Pineda en 1629. Durante un festín indígena, el cacique anfitrión obsequió carneros a sus pares, y al cacique más importante, una oveja de la tierra: "Dispusieron las mujeres hacer fuego, y los muchachones el desollar la carne para que comiesen, despues de haber los caciques degollado cada uno el que le dieron, conforme lo acostumbrado entre ellos; solo la oveja de la tierra quedó en pié, que la reservó el viejo Llancareu (a quien le fue presentada) para llevarla a su tierra, porque son entre ellos de grande estimación, y los que las tienen son hombres de cuenta y podero-

\footnotetext{
${ }^{13}$ Ibid. pp. 176-177.

${ }^{14}$ Ibid. p. 176.

15 Ibid.

${ }^{16}$ Ibid. p. 111.

${ }^{17}$ Ibid. pp. 177-178.
} 
sos". ${ }^{18}$ Del mismo modo, las proporciones numéricas, entregadas por el cronista, evidencian la escasa abundancia de la especie al interior de la Araucanía, en relación al ganado introducido: "salimos aquella tarde de las tierras del cacique nuestro bienhechor y amigo [...]; llevamos por delante dos ovejas de la tierra, dos vacas mansas, tres terneras y veinte ovejas de Castilla". ${ }^{19}$

Es probable que la llama desapareciera definitivamente de la Araucanía como consecuencia del alzamiento general de 1655. En febrero de ese año, los indios "se echaron sobre todos los establecimientos i sobre las estancias del territorio comprendido entre los rios Maule y Biobio. Cautivaron mas de mil trescientas personas españolas. Saquearon trescientas noventiseis estancias. Quitaron cuatrocientas mil cabezas de ganado vacuno, caballar, cabrío i de lana". ${ }^{20}$ El nuevo botín ganadero habría consolidado la crianza de ungulados, por lo que estos animales pasaron a ser predominantes en el paisaje ecológico araucano.

Obedeciendo a criterios prácticos, los mapuches reemplazaron su única especie ganadera por otras que cubrían perfectamente sus requerimientos culturales. La tenencia de ganado caballar, bovino, ovino y caprino satisfizo las demandas de materia prima, alimenticia, social y ceremonial. Por ejemplo, las prolíficas ovejas europeas surtieron la lana con que los mapuches seguirían confeccionaron sus textiles: "vestíanse de sus lanas antes que los europeos descubriesen la América; más ahora que poseen con tanta abundancia los carneros de Europa, no usan de las lanas del chilihueque, sino para tejer algunos jéneros superfinos". ${ }^{21}$

\section{${ }^{18}$ NÚÑEZ DE PINEDA Y BASCUÑÁN,}

FRANCISCO: "Cautiverio Feliz y Razon de las Guerras Dilatadas de Chile". En: Colección de Historiadores de Chile, Imprenta del Ferrocarril, Santiago, 1863, tomo III. p. 49.

${ }^{19}$ Ibid. p. 140.

\section{${ }^{20}$ CARBALLO Y GOYENECHE, VICENTE:}

"Descripcion histórico-jeográfica del Reino de Chile". En: Colección de Historiadores de Chile, Imprenta de la Librería del Mercurio, Santiago, 1875, (tomos VIII, IX y X); tomo IX. pp. 84-85.

${ }^{21}$ MOLINA, JUAN I: "Compendio de la Historia Jeográfica, Natural i Civil del Reino de Chile". En: Colección de Historiadores de Chile, Imprenta del Mercurio, Santiago, 1878, (tomos XI y XXVII); tomo XI, p. 481.
De este modo, al finalizar el siglo XVII, el paisaje ecológico araucano prehispánico había sido transformado por la asimilación e incorporación de las prácticas agroganaderas hispano-mediterráneas. Las alteraciones ambientales, especialmente las relacionadas al ámbito económicoproductivo, modificaron la estructuración ecológica del territorio, generando, paralelamente, importantes cambios culturales.

\section{CONCLUSIONES}

Las condiciones biogeográficas del territorio araucano prehispánico habrían permitido a los indígenas desarrollar una economía diversificada, ecológicamente sustentable. Durante el s. XVI la introducción del modelo agropecuario hispanomediterráneo desarticuló al sistema económico indígena, alterando tempranamente el paisaje ecológico araucano. La abundancia de forraje natural y la ausencia de importantes competidores y depredadores fueron determinantes en la propagación de los ungulados domésticos en la Araucanía. El clima templado y la disponibilidad de suelos prístinos o poco intervenidos en la Araucanía favorecieron la introducción y propagación de las especies vegetales mediterráneas. La propagación de especies vegetales y animales exóticas en la Araucanía se vio también reforzada por las condiciones bélicas, especialmente debido a estrategia de resistencia mapuche, que les permitió obtener y reproducir tanto semillas como ganado introducidos. Durante la segunda mitad del s. XVI y los inicios del s. XVII, coexistieron en la Araucanía especies nativas e introducidas; sin embargo, el s. XVII se caracteriza por un incremento de especies exóticas. A partir de mediados del s. XVII, el predominio de especies introducidas generó notorias modificaciones en el paisaje ecológico de la Araucanía, debido, principalmente, a la desaparición o extinción local de especies animales y vegetales nativas.

\section{AGRADECIMIENTOS}

Investigación financiada por el Proyecto FONDECYT No. 1020224. Los autores desean agradecer a Patricia Martínez y Alberto Araneda por sus revisiones y comentarios.

\section{LITERATURA CITADA}

BENGOA J (1991) Historia del Pueblo Mapuche (siglo XIX y XX). Ediciones Sur, Santiago, Chile. 426 pp. 
BERDICHEWSKY B (1971) Fases culturales en la prehistoria de los araucanos de Chile. Revista Chilena de Historia y Geografía 139: 105-112.

BULLOCK D (1958) La agricultura de los mapuches en tiempos pre-hispánicos. Apartado del Boletín de la Sociedad de Biología de Concepción (Chile): 141154.

CUNILL P (1970) Factores en la destrucción del paisaje chileno: recolección, caza y tala coloniales. Informaciones Geográficas (Chile) (número especial): 235 264.

CUNILL P (1971) Chile meridional criollo: su geografía humana en 1700. Cuadernos Geográficos del Sur (número único): 21-75.

CHONCHOL J (1994) Sistemas agrarios en América Latina, de la etapa prehispánica a la modernización conservadora. Fondo de Cultura Económica S.A., Santiago, Chile. 445 pp.

DÍAZ S, M BONNIN, A LAGUENS \& M PRIETO (1987) Estrategias de explotación de los recursos naturales y procesos de cambio de la vegetación en la cuenca del río Copacabana (Departamento de Ischilin, Provincia de Córdoba). I: mediados del siglo XVI- mediados del siglo XIX. Publicaciones Instituto de Antropología de Córdoba (Argentina) XLV: 67-130.

DONOSO C \& A LARA (1997) Utilización de los bosques nativos en Chile: pasado, presente y futuro. En: Armesto J, C Villagrán \& M Kalin (eds) Ecología de los bosques nativos de Chile: 363-387. Editorial Universitaria, Santiago, Chile.

ENCINA F \& L CASTEDO (1964). Resumen de la historia de Chile. Volumen 1. Empresa Editora Zig-Zag, Santiago, Chile. 736 pp.

GUARDA G (1978) Historia urbana del Reino de Chile. Editorial Andrés Bello, Santiago, Chile. 509 pp.

GUARDA G (1990) Flandes indiano: las fortificaciones del reino de Chile (1541-1826). Ediciones de la Universidad Católica de Chile, Santiago, Chile. 425 pp.
KRUMM G (1971) División territorial de la Araucanía. Revista Chilena de Historia y Geografía (Chile) 139: 87-104.

KRUMM G (1972) División territorial de la Araucanía. Revista Chilena de Historia y Geografía (Chile) 140: 51-71.

LATCHAM R (1915) La capacidad guerrera de los araucanos: sus armas y métodos militares. Revista Chilena de Historia y Geografía (Chile) 19: 22-93.

LATCHAM R (1922) Los animales domésticos de la América precolombiana. Publicaciones del Museo de Etnología y Antropología, Santiago, Chile. 199 pp.

LATCHAM R (1936) La agricultura precolombiana en Chile y los países vecinos. Ediciones de la Universidad de Chile, Santiago, Chile. 336 pp.

LEIVA A (1981-82) La araucanización del caballo en los siglos XVI y XVII. Anales de la Universidad de la Frontera (Chile): 181-203.

MARTÍNEZ C (1998) Nuestros paisanos los indios. Emecé Editores S.A., Buenos Aires, Argentina. 659 pp.

MOSTNY G (1996) Prehistoria de Chile. Decimotercera edición. Editorial Universitaria, Santiago, Chile. 185 pp.

PACHECO A (1991) Una economía de conquista, Concepción siglo XVI. Revista de Historia Universidad de Concepción (Chile) 1: 25-44.

VILLALOBOS S (1983) Historia del pueblo chileno. Editora Zig-Zag, Santiago, Chile. Volumen I. 228 pp; Volumen II, 277 pp.

VILLALOBOS S (1995) Vida fronteriza en la Araucanía, el mito de la guerra de Arauco. Editorial Andrés Bello, Santiago, Chile. 215 pp.

ZAPATER H (1985) Parlamentos de paz en la guerra de Arauco. En: Villalobos S \& J Pinto (eds) Araucanía temas de historia fronteriza: 47-82. Ediciones Universidad de la Frontera, Temuco, Chile. 